Wilza Vieira Villela ${ }^{1}$ Regina Maria Barbosa ${ }^{2}$

\section{Trajetórias de mulheres vivendo com HIV/aids no Brasil. Avanços e permanências da resposta à epidemia}

\author{
Trajectories of women living with HIV/AIDS in Brazil. \\ Progress and permanence of the response to the epidemic
}

Abstract This article analyzes the trajectories of 85 women living with HIV/AIDS in six Brazilian cities: Belém, São Paulo, Ribeirão Preto, Goiânia, Recife and Pelotas, to understand some specific aspects of their experiences before and after diagnosis. It is based on in-depth interviews conducted in 2009 addressing women diagnosed with HIV between 1 and 20 years previously. The results show a profile characterized by limited access to school, health services and labor and a marked presence of violence. The reasons for applying HIV tests vary over time and there is an increase in prenatal testing, although no modifications in the context of the infection are apparent. For some women, the diagnosis determines changes in lifestyle. However, for the majority, social and labor experiences and the decisions about love, sexuality and reproduction seem to respond to their immediate demands and opportunities. The management of the diagnosis and the support received influence living with HIV/AIDS. These results show the need for actions for prevention and testing not restricted to pregnant women, even in the context of a concentrated epidemic. Studies adopting a biographical perspective can contribute to prevent or improve living with HIV/AIDS appropriate to the different moments of the womens' trajectories. Key words Trajectories, Health, Gender, Women, HIV/AIDS
Resumo Este artigo analisa as trajetórias de 85 mulheres vivendo com HIV/aids em seis cidades brasileiras, Belém, São Paulo, Ribeirão Preto, Goiânia, Recife e Pelotas, visando apreender suas experiências de vida antes e depois da infeç̧ão. Utiliza como material empírico entrevistas em profundidade realizadas em $2009 \mathrm{com}$ mulheres com tempo de diagnóstico entre 1 e 20 anos. Os resultados mostram um perfil de limitado acesso à escola, serviços de saúde e mercado de trabalho, e forte presença de violência. O motivo de realização do diagnóstico varia ao longo do tempo, com aumento da testagem no pré-natal; entretanto, os contextos de infecção parecem não se alterar. $O$ diagnóstico determina mudanças na vida de algumas mulheres, mas a sua inserção social, laboral e as decisões relativas à vida amorosa, sexual e reprodutiva parecem responder às suas demandas imediatas. O modo de lidar com o diagnóstico e os apoios recebidos influenciam o convívio com o HIV. Estes resultados mostram a necessidade de ações de prevenção e diagnóstico não restritas a gestantes, mesmo num contexto de epidemia concentrada. Estudos que adotem uma perspectiva biográfica podem contribuir para ações de prevenção ou construção da vida com o HIV/aids adequadas aos diferentes momentos das trajetórias das mulheres.

Palavras-chave Trajetórias, Saúde, Gênero, Mulheres, HIV/aids

${ }^{2}$ Universidade Estadual de

Campinas. Campinas SP

Brasil. 


\section{Introdução}

Na investigação em saúde, cada vez mais o constructo "trajetórias" tem sido utilizado como dispositivo metodológico que permite articular os fatos da biografia de um sujeito aos seus determinantes contextuais ${ }^{1}$. A construção de trajetórias em relação a um determinado aspecto da vida permite que dados objetivos e quantificáveis ganhem sentidos específicos quando organizados numa perspectiva temporal singular, possibilitando sua análise a partir de interpretações qualitativas ${ }^{2}$.

Um dos pressupostos que fundamenta o uso das trajetórias na investigação em saúde é o reconhecimento da complexidade que envolve o tema. Práticas e concepções relativas à saúde variam ao longo do tempo e do momento da vida de cada um; entretanto, uma ação ou decisão tomada num dado momento interfere no curso da vida e determina situações posteriores ${ }^{3}$. Ao mesmo tempo, estas ações e decisões se inscrevem em contextos de vida marcados social e culturalmente, que circunscrevem as possibilidades de escolhas e atribuem sentidos a estas, delimitando capacidades e recursos para o manejo das situações vivenciadas ${ }^{4}$.

Deste modo, as trajetórias de saúde se constroem no cruzamento entre dimensões subjetivas e individuais e contextos socioculturais. Seu estudo permite compreender o sentido das decisões e práticas que irão constituir a história da saúde de um indivíduo ou grupo, não apenas sob o ponto de vista das suas narrativas, mas também na perspectiva dos seus determinantes.

No caso das mulheres e dos agravos à sua saúde, as injunções das desigualdades de gênero nas suas decisões e oportunidades tornam a abordagem das trajetórias especialmente promissora. Em particular no que se refere às questões sexuais e reprodutivas, dada a densa gama de significados culturais que envolvem seu exercício e a relativa menor autonomia das mulheres nesta área ${ }^{5}$.

O mesmo pode ser dito em relação à infecção pelo HIV entre mulheres. Além de explicitar as desigualdades de gênero no exercício da sexualidade e da reprodução, a infecção pelo HIV na população feminina apresenta uma dinâmica específica. A maioria das mulheres não se identifica com os grupos e comportamentos considerados de maior risco para a infecção, o que dificulta sua percepção de risco e uso de proteção ${ }^{6}$; aspectos da vida sexual e reprodutiva se alteram, seja pela necessidade de uso do preservativo ou pelo temor de transmissão para o parceiro ou para o recémnascido, entre aquelas já infectadas ${ }^{7}$. Ademais, vale ressaltar o menor engajamento político das mulheres no enfrentamento da epidemia e do estigma relacionado ao HIV/aids, o que confere maior solidão ao processo de elaboração da sua convivência com a infecção ${ }^{8}$.

Alguns estudos têm apontado a importância de compreender aspectos da exposição ao HIV entre mulheres por meio da análise das suas trajetórias sexuais e conjugais ${ }^{9}$, ou ainda de suas decisões reprodutivas após o diagnóstico em função das suas trajetórias reprodutivas antes do mesmo ${ }^{10}$. Nesta direção, estudos realizados no início dos anos 2000 já haviam indicado que a intenção de ter filhos entre mulheres vivendo com HIV estava mais influenciada pelo tamanho de suas famílias do que pelo diagnóstico ${ }^{11}$. Pesquisas mais recentes, apontam que a indução do aborto entre mulheres vivendo com HIV/aids no Rio Grande do Sul deve ser interpretada à luz das suas trajetórias reprodutivas, e não apenas da infecção pelo HIV ${ }^{12,13}$, confirmando achados de estudos anteriores ${ }^{14}$. A utilização da perspectiva das trajetórias também foi utilizada para analisar os recursos e as estratégias de enfrentamento do estigma entre gestantes vivendo com HIV/aids no Rio de Janeiro ${ }^{15}$.

Outros estudos sobre mulheres vivendo com HIV apontam contextos de vulnerabilidade social e violência como uma das marcas da dinâmica do HIV/aids no contexto feminino, sugerindo que esta infecção se inscreve em um âmbito de desigualdade de gênero e de exclusão social já vivenciado anteriormente e, de alguma forma, a ele relacionada. Também tem sido apontada uma gama de fatores morais, culturais, religiosos e relativos ao gênero que interferem nas decisões das mulheres vivendo com HIV em relação à sua vida afetiva, sexual e reprodutiva tanto antes quanto depois do diagnóstico ${ }^{16}$.

Ressalte-se que após a primeira década de epidemia, marcada pelo predomínio de casos entre homens, o aumento da infecção entre mulheres na década de 1990 fomentou um grande número de estudos e intervenções voltados para este grupo. Com a mudança do perfil epidemiológico da infecção pelo HIV/aids no país e a relativa estabilização do seu crescimento entre mulheres a partir dos anos 2000, esta produção teve seu volume reduzido. Hoje o Brasil é considerado um país de epidemia concentrada, na qual as mulheres não constituem um grupo populacional prioritário, apesar da notificação de novos casos 
entre elas e do aumento da taxa de detecção entre gestantes ${ }^{17}$. Em 2014 esta taxa foi de 2,6 gestantes por 1000 nascidos vivos, com diferenças entre as regiões e estados da federação. A maioria das gestantes identificadas como soropositivas tinha de 20 a 29 anos de idade, estudou até, no máximo, a oitava série e em termos de raça/cor não se classifica como branca ${ }^{17}$, sugerindo a persistência de características de vulnerabilidade social já apontada anteriormente em estudos sobre a epidemia do HIV/aids no Brasil ${ }^{18}$.

A não prioridade das mulheres no cenário da epidemia brasileira faz com que as ações voltadas para este grupo populacional se mantenham restritas à identificação de gestantes com HIV visando à prevenção da transmissão para a criança, o que limita o acesso das não grávidas ao diagnóstico e ao início oportuno do tratamento.

Diagnóstico e tratamento precoces têm sido cruciais para a redução da mortalidade por aids. Entretanto, para que o diagnóstico seja realizado, que o tratamento seja iniciado de forma oportuna e que haja adesão, são necessários, além destes recursos biomédicos, suportes psicossociais que contribuam para a aceitação do diagnóstico e elaboração de formas de convívio com a infecção que permitam o desfrute da vida e a continuidade dos projetos que lhe dão sentido. A garantia de uma vida com qualidade, apesar do HIV, exige o manejo contínuo dos conflitos decorrentes do diagnóstico e das suas repercussões no cotidiano e nas decisões a serem tomadas, de modo a atender as demandas necessárias à construção do viver com HIV/aids que surgem no processo de "normalização" da vida pós-diagnóstico ${ }^{19}$.

Neste sentido, o estudo das trajetórias de mulheres vivendo com HIV/aids pode contribuir para o entendimento das situações que condicionam a exposição ao vírus, especialmente aquelas relacionadas às diferentes formas de exclusão social, como também das consequências da infecção no delineamento dos percursos de cada sujeito a partir de seu diagnóstico. Deste entendimento podem derivar ações voltadas para apoiar as mulheres nas suas decisões pós-diagnóstico, cumprindo a diretriz de integralidade que orienta as políticas e as práticas no âmbito do Sistema Único de Saúde - SUS. Este artigo analisa as trajetórias de vida de mulheres vivendo com HIV/ aids no Brasil, antes e depois da infecção, buscando identificar possíveis influencias das situações de exclusão social e desigualdades de gênero nas formas de elaboração da convivência com HIV.

\section{Metodologia}

Os dados analisados neste artigo são oriundos de um estudo mais amplo, realizado em 2009, no qual foram entrevistas em profundidade $85 \mathrm{mu}$ lheres entre 18 e 49 anos vivendo com HIV em seis cidades brasileiras - Belém, Goiânia, Porto Alegre, Pelotas, Recife, Ribeirão Preto, São Paulo.

A estratégia para compor o grupo de mulheres buscou contemplar diversidade em termos de raça/cor, idade, inserção social e trajetórias sexuais e reprodutivas. O convite para participar do estudo se deu majoritariamente nos serviços de saúde especializados em DST/Aids nas cidades selecionadas, por meio de contato feito pelas entrevistadoras ou intermediado por profissionais destes serviços. Após este primeiro contato, as entrevistas foram agendadas em dia, hora e local de conveniência para a entrevistada, sendo gravada após consentimento da mulher e assinatura do TCLE. O roteiro de entrevistas foi desenvolvido na perspectiva das trajetórias, buscando identificar acontecimentos e fatores que influenciaram decisões relativas aos temas considerados, a saber: vida familiar e entorno; acesso à escolarização, saúde e trabalho; vida afetiva, sexual e reprodutiva; contexto da infecção pelo HIV, decisões reprodutivas antes e depois do diagnóstico e manejo do estigma associado ao HIV/aids.

Para a análise dos dados, após a transcrição e a leitura das entrevistas, foi reconstruída a trajetória de cada mulher. Para tanto, considerouse a sequência temporal de cada um dos eventos abordados e os sentidos atribuídos pelas entrevistadas aos seus posicionamentos e decisões em cada etapa da sua biografia. Após esta etapa os depoimentos relativos a cada um dos temas propostos foram organizados em blocos temáticos, e seu conteúdo foi categorizado considerando experiências e decisões antes e depois da infecção. Em seguida, os depoimentos incluídos em cada categoria foram analisados buscando-se identificar semelhanças e diferenças nas experiências das mulheres após a infecção. Finalmente, as semelhanças e as divergências identificadas foram relacionadas com as trajetórias individuais, visando estabelecer possíveis nexos entre os dois conjuntos de dados. Todo este processamento foi feito com a utilização do software MaxQDA.

O projeto foi aprovado pelo Comitê de Ética do CRT/aids-SP. 


\section{Resultados}

\section{Características das mulheres}

A distribuição das entrevistadas nas seis cidades onde o estudo foi realizado não é homogênea, tendo havido um número menor de entrevistas em Goiânia e em Pelotas/Porto Alegre, sendo estas duas últimas cidades consideradas como uma unidade de coleta. A maioria das entrevistadas tinha entre 30 e 39 anos e dezoito mulheres, entre 18 e 29 anos. Trinta e três mulheres, menos da metade, se classificou com branca e apenas duas, como indígenas. As demais se identificaram como pretas ou pardas.

Trinta e nove entrevistadas não haviam completado o ensino fundamental, e vinte e oito possuíam o segundo grau completo ou curso superior, completo ou incompleto. Mais de metade das mulheres trabalhava no momento da entrevista; entre as que não trabalhavam contam-se as aposentadas, as pensionistas e as desempregadas. Praticamente todas referiram ter trabalhado em algum momento da vida. As mulheres com menor escolaridade apresentaram inserção mais precoce no mercado de trabalho, com ocupações que não exigiam formação profissional específica, como trabalhadoras domésticas ou vendedoras. Quinze mulheres afirmaram ser ou terem sido trabalhadoras sexuais. A maioria das entrevistadas iniciou a vida sexual antes dos 18 anos. A falta de informações sobre sexualidade e contracepção e quase nenhum contato com serviços de saúde até a primeira gravidez são características do período inicial de suas trajetórias.

Há um grande número de relatos de desagregação e violência intrafamiliar, incluindo espancamento da mãe pelo pai ou da própria mulher, ainda criança, por seus responsáveis. Há também histórias de violência sexual, seja por familiares ou conhecidos, durante a infância, ou por desconhecidos na adolescência ou idade adulta. $\mathrm{Ne}$ nhuma mulher referiu estar vivendo situações de violência no momento da entrevista. A Tabela 1 sumariza algumas das características das entrevistadas.

\section{Trajetórias pós infecção}

Os contextos de aquisição da infecção, embora distintos, são permeados por histórias de amor, de pressão dos parceiros por sexo e/ou para o sexo sem preservativo, como também por desinformação sobre a infecção pelo HIV/aids e a necessidade de proteção. O tempo de diagnós- tico variou de menos de 1 a 21 anos. No relato das mulheres com maior tempo de infecção foi frequente a referência a infecções oportunistas ou adoecimento do parceiro como motivo da realização do teste. Para aquelas com diagnóstico mais recente, há um número expressivo destes terem sido realizados durante o pré-natal.

As repercussões do HIV na vida das mulheres variam, tanto em função do tempo de diagnóstico como dos apoios e suportes recebidos. Algumas referem ter restringido seu círculo de amizades e suas atividades sociais e de lazer, e aproximação da família. Outras pararam de trabalhar, seja para cuidar da saúde, da família, ou porque foram demitidas, em função do HIV ou não. Em termos de vida sexual e afetiva, algumas permaneceram com os parceiros da época do diagnóstico, outras iniciaram novas relações. Do mesmo modo, na esfera reprodutiva algumas optaram por não ter mais filhos por medo destes serem portadores ou por receio de morrer e deixar a criança. Outras, no entanto, optaram por manter sua vida reprodutiva até ter o número desejado de filhos.

Embora apenas 16 mulheres refiram experiências de estigma, a revelação seletiva do diagnóstico ou a opção de não revelá-lo, mesmo para pessoas próximas, como filhos, parceiros, irmãos ou pais, reflete o processo de estigma relacionado à infecção. A Tabela 2 sintetiza aspectos referentes a circunstancias da infecção e diagnóstico e trajetórias após este de acordo com o tempo de realização do mesmo:

Como já referido, situações como a circunstância de realização do diagnóstico, sua aceitação, compartilhamento com pessoas próximas e busca de apoio variam com o tempo de convivência com o HIV. Outras situações, em especial no que se refere a saber como se deu a infecção, parecem alterar-se menos. Tanto mulheres diagnosticadas há mais de 10 anos quanto as que recém se infectaram têm dificuldade de saber como ou com quem se deu a infecção.

A relação entre a exposição a situações de vulnerabilidade, os contextos de infecção e a forma como cada mulher lida com esta não é linear. Cada situação vivenciada adquire caráter singular em trajetórias específicas. Alguns fragmentos dos depoimentos podem ilustrar este ponto.

$\mathrm{AL}$, por exemplo, presenciou várias agressões do seu pai contra sua mãe, sendo também espancada com frequência. Fugiu de casa aos 12 anos e teve o primeiro filho aos 13. Trabalhou desde criança e estudou até o segundo grau. Conhece sua sorologia há mais de 10 anos, atribuindo a infecção a um dos três parceiros que teve antes do 
Tabela 1. Distribuição das entrevistadas segundo local das entrevistas e características selecionadas.

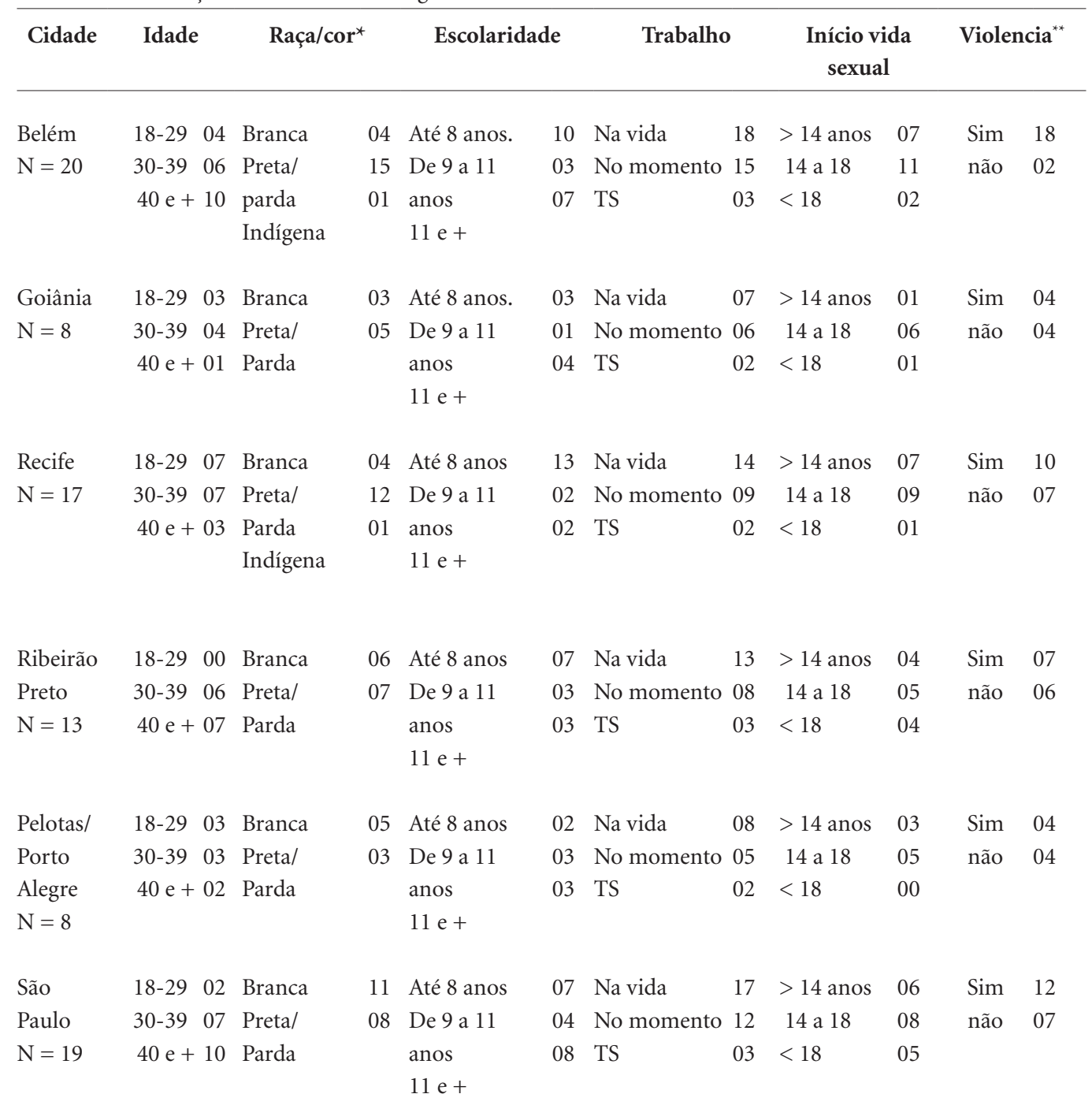

*Autoclassificação. ${ }^{* *}$ Inclui ter sido espancada por pai, mãe, ou avós; ter sofrido violência física por parceiro e ter sofrido violência sexual em qualquer idade.

atual. Desde o início compartilhou seu diagnóstico com a família e assume sua soropositividade. É a única entrevistada engajada em atividades políticas voltadas para os direitos das pessoas vivendo com HIV. Seu depoimento é ilustrativo:

...meus filhos escutavam quando eu faço alguma entrevista. A mãe de vocês é aidética né? Aí, a minha filha toda bonitinha, ela cruza as pernas e minha mãe não é aidética, minha mãe é uma cidadã positiva...

A revelação do diagnóstico, no entanto, não acontece sempre, e muitas mulheres referem vergonha da sua condição e mesmo preconceito com outros portadores. MG, por exemplo, embora também tenha fugido de casa aos 12 anos, por conta da violência presenciada e sofrida, constrói uma trajetória distinta. Interrompeu os estudos no primeiro grau, trabalhou de forma irregular e teve seu primeiro filho aos 17 anos. Conheceu sua sorologia cinco anos antes da entrevista, quando realizou o pré-natal do segundo filho. Não sabe como se infectou, não procura saber e busca manter seu diagnóstico preservado por temer o preconceito, embora a sua experiência não confirme este temor, mesmo em se tratando de relacionamentos amorosos: ...eu já tive um relacionamento duradouro e inclusive eu contei pra essa pessoa que eu tinha. No inicio foi difícil ele ficou meio surpreso e tal mas depois ele continuou comigo... 
Tabela 2. Circunstâncias da infecção e diagnóstico e mudanças de vida segundo tempo de diagnóstico.

\begin{tabular}{|c|c|c|c|c|}
\hline Tempo de infecção & $\begin{array}{c}<1 \text { ano } \\
n=8\end{array}$ & $\begin{array}{c}1 \text { a } 4 \text { anos } \\
n=15\end{array}$ & $\begin{array}{c}5 \text { a } 10 \text { anos } \\
n=30\end{array}$ & $\begin{array}{c}>10 \text { anos } \\
n=32\end{array}$ \\
\hline \multicolumn{5}{|l|}{ Circunstância do diagnóstico: } \\
\hline Pré-natal/parto & 4 & 7 & 9 & 3 \\
\hline Sintoma/iniciativa própria & 2 & 6 & 16 & 20 \\
\hline Sintoma do parceiro & 2 & 2 & 5 & 9 \\
\hline Aceitação do diagnóstico & 4 & 9 & 21 & 23 \\
\hline Identifica como adquiriu o vírus & 5 & 8 & 16 & 19 \\
\hline \multicolumn{5}{|l|}{ Mudanças na vida } \\
\hline Novos relacionamentos & 2 & 4 & 10 & 13 \\
\hline Parou vida sexual ou amorosa & 3 & 3 & 6 & 6 \\
\hline Mais cuidado com a saúde/ preocupação com futuro & 3 & 8 & 3 & 5 \\
\hline Teve filhos após diagnóstico & & 4 & 4 & 9 \\
\hline Decidiu não ter mais filhos & 3 & 3 & 6 & 12 \\
\hline Deixou de fazer coisas que fazia & 2 & 4 & 9 & 7 \\
\hline Iniciou novos projetos de vida & 1 & 3 & 6 & 8 \\
\hline Esconde a sorologia de amigos/ familiares/parceiros & 5 & 6 & 7 & 8 \\
\hline Buscou/recebeu apoios & 2 & 8 & 12 & 11 \\
\hline Refere situações de estigma ou discriminação & 2 & 3 & 6 & 5 \\
\hline
\end{tabular}

O que se percebe, portanto, é uma ambiguidade quanto à revelação da sorologia que expressa tanto a persistência do estigma em relação ao HIV como a sua introjeção:

Pras pessoas que eu já contei nenhuma mudou comigo, mas tem gente que não tem informação [...] Eu poderia contar pra qualquer pessoa, eu não tenho vergonha, mas não é preciso [...] porque se outras pessoas sabem do meu problema, já vai ter discriminação né.

Ao mesmo tempo, tanto a fala de MG quanto a de outras entrevistadas aponta a construção de um cotidiano com, e apesar, do HIV: Eu to bem, eu só lembro disso quando eu vou lá no hospital, no meu dia-a-dia eu nem lembro.

Se estes dois fragmentos mostram modos distintos de lidar com a infecção e o diagnóstico entre mulheres com a vida igualmente marcada pela violência e pela pobreza, outros relatos contribuem para reiterar esta diversidade. MT tem 34 anos e conhecia seu diagnóstico há pouco mais de um ano, tendo dificuldade de aceita-lo. Segundo ela ... as vezes eu não acredito, fico pensando assim. Como foi? Por que foi? MT também era pobre, foi espancada pelo pai e presenciou o assassinato de um irmão. Entretanto, permaneceu com a família, estudou até a metade do segundo grau e tem uma profissão definida. Também não sabe como se infectou e não contou para ninguém da infec- ção: Só minha filha, mais ninguém sabe. Eu não espero contar pra ninguém, nem pra minha família, amizade, nem pra essa pessoa que eu to ficando, nem pra ele mesmo eu pretendo contar.

Nas trajetórias destas três mulheres, a forma de lidar com a soropositividade parece estar relacionada ao tempo de conhecimento do diagnóstico e ao aprendizado de viver com o HIV. Suas experiências anteriores de violência ou o acesso à escola, embora importantes na construção da vulnerabilidade à infecção, não parecem predizer o que irá acontecer nas suas vidas pós-diagnóstico.

Ressalte-se ainda a importância de diferentes formas de apoio na construção da vida com HIV. EL, por exemplo, tem 36 anos, segundo grau completo, nunca viveu situações de violência na família e/ou por parceiros, e sabe como se infectou, conhecendo seu diagnóstico há quinze anos. Segundo ela, ... desde o início meus pais abriram os braços pra mim, me deram o maior apoio. A infecção, no entanto, a fez mudar seu círculo de amizades, hoje formado principalmente por pessoas que também vivem com HIV.

No relato de MR, que completou o segundo grau e sempre teve um trabalho regular, o que aparece como decisivo na elaboração da convivência com o HIV foi o suporte recebido no espaço de trabalho: Aí eu pensei, vou pedir a conta, 
ir pra outra cidade, fugir de tudo. Mas aí meu chefe me deu apoio, não aceitou a minha demissão, não cortou nenhum dia. MR conhecia seu diagnóstico há 10 anos no momento da entrevista e, como muitas das entrevistadas, sabia como e com quem se infectou - seu parceiro estável, com quem tinha relações desprotegidas por não se supor em risco.

Em muitas histórias é possível identificar a articulação entre o tempo de infecção e a busca por suportes e apoios. $\mathrm{O}$ constrangimento e o silêncio que sucedem de imediato o diagnóstico dificulta a procura de ajuda. Entretanto, na medida em que o manejo da condição de soropositividade vai se tornando quase uma exigência para o cumprimento dos demais compromissos que a vida impõe, alguns recursos começam a ser acessados e o diagnóstico vai sendo compartilhado, em função das demandas e necessidades sentidas.

No entanto, nem sempre o tempo decorrido desde o diagnóstico ou as possibilidades de apoio são suficientes para que a mulher estabeleça formas de viver com o HIV que não impeçam o lazer, o prazer e a sociabilidade. O relato de AJ, 36 anos, que conhece a sua sorologia há 14 anos, é ilustrativo. AJ não completou o primeiro grau e trabalhou como doméstica até se aposentar por invalidez em função do HIV. Segundo ela: Eu gostava de sair, hoje não saio mais [...] tenho medo de encontrar homem que queira ficar comigo, eu não quero. Não vou querer prejudicar ninguém.

\section{Discussão}

Em função da época em que foram realizadas as entrevistas e da variabilidade do tempo de conhecimento do diagnóstico, é possível observar situações que se referem a períodos distintos da epidemia no país e da construção da resposta nacional. Assim, há entrevistadas que se infectaram ao final dos anos 80 e início da década de 90, quando a epidemia começava a se tornar visível entre mulheres que não eram profissionais do sexo e não havia política pública específica para este grupo populacional. Existem também aquelas que se infectaram ao longo da década de 90, quando o rápido avanço da epidemia entre mulheres cunhou a expressão "feminização da epidemia”, apontando não apenas para este fato como também para a desconstrução da ideia dos "grupos de risco"20. As mulheres infectadas neste período começam a se beneficiar da política pública voltada para oferta de testagem no prénatal, implementado como forma de ampliar e antecipar o diagnóstico entre mulheres e, principalmente, para reduzir a transmissão do HIV para o recém-nascido de uma portadora. Há semelhança entre as trajetórias das entrevistadas e aquelas identificadas em estudos anteriores ${ }^{11,14,18}$ e posteriores ${ }^{15}$, sugerindo uma persistência na dinâmica da vulnerabilidade das mulheres ao HIV que não foi afetada pelo tempo decorrido entre a realização das entrevistas e a atual análise.

As mudanças e as permanências na história da epidemia, seja no seu perfil epidemiológico ou nas ações de enfrentamento, se expressam nas trajetórias das mulheres entrevistadas. Assim, o número de mulheres que em algum momento foram trabalhadoras sexuais confirma a vulnerabilidade deste grupo ao HIV; ao mesmo tempo, a análise das suas trajetórias aponta que esta circunstancia nem sempre se constitui como uma identidade pessoal ou profissional, como já apontado em outros estudos ${ }^{14}$. Se o perfil de baixa escolaridade, precária inserção laboral e violência na vida caracteriza as mulheres vivendo com HIV/aids desde o início da epidemia no país, a redução daquelas que tiveram diagnóstico em função dos sintomas dos parceiros, e o aumento proporcional das que conheceram a sua sorologia positiva no pré-natal aponta para o efeito da oferta de testagem nesta ocasião ou no parto, tornada política pública desde meados dos anos $90^{20}$.

Entretanto, se não parece haver mudanças no perfil das entrevistadas, também os contextos de infecção parecem não variar muito ao longo do tempo. O não uso do preservativo é atribuído à presença da relação estável, à não percepção do risco ou mesmo à dificuldade de uso de proteção junto a um parceiro eventual. Ou seja, apesar do esforço de organizações governamentais e não governamentais, em especial na década de 90, visando desconstruir a ideia dos "grupos de risco" e incentivar a negociação para o uso do preservativo, esta ideia parece que se manteve no imaginário social e a prática de prevenção continua um desafio, especialmente quando a mulher estabelece vínculos afetivos e de confiança com o parceiro $^{21}$. De fato, a persistência do estigma relacionado ao HIV/aids e seus portadores continua a fomentar atribuições negativas ao uso do preservativo, restringindo a prevenção entre as mulheres, mesmo nos dias atuais ${ }^{22}$.

Deve também ser considerada a ausência de uma política pública mais ampla e efetiva nesta direção. O apoio governamental a iniciativas da sociedade civil visando discutir os padrões desiguais do exercício da sexualidade entre mulheres e homens e suas consequências para a saúde, e a 
realização de algumas campanhas neste sentido, não se constituíram em ações sistemáticas visando à prevenção do HIV/aids entre mulheres em qualquer fase da vida, em que pese a formulação, em 2007, do Plano Integrado de Enfrentamento à Feminização da aids e outras DST ${ }^{23}$.

Dentre as mulheres inseridas na prostituição em algum momento da vida, nem todas relacionam a sua infecção a este trabalho, seja por terem se infectado antes ou por atribuírem a infecção a um parceiro específico e não a um cliente desconhecido. Este é um tema que merece ser melhor investigado, dado que a recusa destas mulheres em relacionar seu trabalho na prostituição à infecção pelo HIV pode apontar um perfil de vulnerabilidade ao vírus no qual essa ocupação se inclui, mas não é determinante. $\mathrm{O}$ estigma relacionado à prostituição e sua articulação com a infecção pelo HIV na produção da ideia de "grupos de risco" 24 também pode contribuir para que as mulheres relutem em associar seu trabalho à infecção. Ressalte-se que para várias entrevistadas a resistência em expor a sua soropositividade se relacionou ao temor de que a infecção fosse atribuída a alguma forma de promiscuidade sexual, conforme também apontado por Monteiro et al. ${ }^{15}$.

O temor do preconceito e da discriminação não impede que as mulheres continuem suas vidas, muitas estabelecendo novos relacionamentos, projetos de vida ou completando suas trajetórias reprodutivas. A possibilidade de novas relações aumenta com o tempo, do mesmo modo que as preocupações com o futuro tendem a diminuir, sugerindo que viver com HIV/aids é um aprendizado.

As trajetórias apresentadas mostram a diversidade de escolhas realizadas e de estratégias utilizadas para organizar a vida após o diagnóstico. Para algumas mulheres, a possibilidade de viver com o HIV está relacionada aos apoios sociais mobilizados e à manutenção de laços familiares e afetivos, apontando para a importância desses vínculos na qualidade de vida sendo portadoras do vírus ${ }^{25}$. Para outras, entretanto, os vínculos sociais se restringem, sendo estabelecidos novos círculos de relações em que a infecção passe despercebida ou não valorizada.

No entanto, o processo de estabelecimento de novos vínculos pós-diagnóstico não incluiu a inserção em movimentos de defesa de direitos das pessoas com HIV, uma das principais estratégias desenvolvidas nas primeiras décadas da epidemia para o enfrentamento do estigma associado ao vírus e a construção do viver com HIV/aids ${ }^{26}$. A menor participação de mulheres nestes espaços, predominantemente masculinos, pode ser compreendida, em parte, pelos sentidos atribuídos à infecção nas mulheres - "vítimas" dos seus parceiros, em contraste com o sentido "transgressivo” da infecção entre homens gays ou usuários de drogas, embora outros motivos também possam ser aventados. No entanto, é fato que a menor participação das mulheres, em termos quantitativos e qualitativos, nas organizações comunitários de luta contra Aids, tem dificultado a elaboração de uma agenda política voltada para a desconstrução do estigma relacionados ao HIV na perspectiva feminina. Esta falta de representação também fragiliza a reivindicação por ações públicas de saúde voltadas para a prevenção, o diagnóstico precoce e o manejo da infecção em todas as fases da vida das mulheres.

A presença da violência na vida das entrevistadas coincide com o que tem sido considerado outro importante desafio para a redução da vulnerabilidade das mulheres à infecção. Chama a atenção as formas distintas com que as mulheres lidaram com esta circunstância ao longo das suas vidas. Algumas reproduziram, nas suas relações amorosas e conjugais, as relações abusivas que haviam vivenciado nas suas casas, mas outras romperam com o ciclo de violência e estabeleceram novos padrões de relacionamento afetivo e familiar, independente da sua situação de pobreza, da baixa escolaridade e da infecção pelo HIV. Ou seja, há uma capacidade de agência, por parte das mulheres, que deve ser valorizada para que não sejam reduzidas a vítimas, seja de um parceiro infiel ou violento ou de uma família desestruturada ${ }^{27}$. O reconhecimento desta capacidade de agência é fundamental para a compreensão das suas escolhas e na construção da vida com HIV/aids.

\section{Comentários finais}

A análise do perfil das entrevistadas mostrou um quadro de vulnerabilidade social, expresso pelo baixo nível de escolaridade, precária inserção no mercado de trabalho e presença de violência na vida, que se coaduna com o perfil das mulheres vivendo com HIV/aids no país ao longo dos anos de epidemia. A persistência deste perfil mostra que a perversa relação entre Aids e desigualdades sociais e de gênero é um desafio ainda não superado $^{28}$. Mas também sugere peculiaridades em relação à epidemia entre mulheres, que devem ser consideradas na formulação das ações que compõem a resposta nacional. Em especial no que se refere à oferta de ações de prevenção e diagnósti- 
co não restritas a profissionais do sexo e gestantes, mesmo num contexto de epidemia concentrada.

Existem aproximadamente 280.000 mulheres vivendo com HIV no Brasil ${ }^{29}$. Este estudo, ao abordar trajetórias de mulheres com características distintas e vivendo em diferentes partes do país, aponta para a necessidade de se adequar as ações de cuidado em função dos contextos que se apresentam ao longo dessas trajetórias. Ações estratégicas voltadas para o enfretamento de uma epidemia concentrada podem levar ao negligenciamento de populações não prioritárias, cujo cuidado exige ajustes cotidianos.

A proporção de mulheres que já se prostituíram no conjunto das entrevistadas reproduz aproximadamente o quadro da epidemia no país, no qual as trabalhadoras sexuais são uma parcela menor das que vivem com HIV/aids, embora com maior prevalência de infecção, o que reitera a importância de ações específicas para este grupo ao lado daquelas de caráter populacional voltadas para mulheres em qualquer fase da vida.

A diversidade de experiências analisadas aponta para a importância de estratégias de prevenção e de construção de um "viver com HIV/ aids" para mulheres que combinem intervenções de cunho individual com medidas estruturais mais amplas de redução das desigualdades sociais e de gênero. Informações corretas sobre o HIV, ações educativas em sexualidade nas escolas e fora delas, enfrentamento da violência de gênero, dentre outras, podem contribuir para que as mulheres tenham mais recursos para se prevenir da infecção e viver com o HIV/Aids. Ademais, devem ser proporcionadas às mulheres com diferentes tempos de diagnóstico possibilidades de elaboração e compartilhamento das suas experiências de viver com HIV/aids.

O estigma relacionado ao HIV/aids é um dos grandes obstáculos para a prevenção entre as mulheres, que não se identificam, nem seus parceiros, com os estereótipos construídos em torno da epidemia, e ainda para a construção de uma vida de qualidade em presença da infecção. Assim, enfrentar o estigma associado ao HIV/aids entre a população feminina continua sendo uma prioridade.

A utilização da abordagem das trajetórias, apresentada neste estudo, permitiu identificar a diversidade de experiências relativas à infecção pelo HIV entre mulheres, considerando aspectos referentes à infecção e ao manejo do diagnóstico e da condição de soropositividade ao longo da vida. Além disso possibilitou a análise das repercussões de algumas políticas e ações de saúde, como a oferta de testagem no pré-natal na realização do diagnóstico.

Ao mesmo tempo apontou a persistência de padrões de relacionamento amoroso e sexual entre homens e mulheres que acabam por expô-las ao risco da infecção, e as repercussões negativas do estigma relacionado ao HIV/aids para o manejo da soropositividade. No que se refere a questões sexuais e reprodutivas, a abordagem das trajetórias mostrou que a infecção pelo HIV não necessariamente significa um obstáculo para que as mulheres realizem seus projetos amorosos e reprodutivos, sugerindo a importância do apoio dos serviços de saúde às suas decisões nesse âmbito. O diagnóstico determina mudanças na vida de algumas mulheres, mas a sua inserção social, laboral e as decisões relativas à vida amorosa, sexual e reprodutiva parecem responder às suas demandas imediatas ou oportunidades que lhes são apresentadas. Cabe, portanto, reconhecer a capacidade de agenciar das mulheres na construção das suas trajetórias.

Por ser este um estudo qualitativo, os resultados não podem ser generalizados. Entretanto, as tendências indicadas na análise dos resultados sugerem que estudos que adotam uma perspectiva biográfica podem ser úteis para identificar lacunas na construção de respostas à infecção pelo HIV entre mulheres.

\section{Colaboradores}

WV Villela e RM Barbosa contribuíram igualmente no delineamento e realização da pesquisa que deu origem a este manuscrito, e na sua elaboração. 
Referências

1. Burton-Jeangros C, Cullati S, Sacker A, Blane D, editors. A Life Course Perspective on Health Trajectories and Transitions. London: OA Books; 2015.

2. Born C. Gênero, trajetória de vida e biografia: desafios metodológicos e resultados empíricos. Sociologias 2001; 3(5):240-265.

3. Gray E, MacDonald P. Using a reproductive life course approach to understand contraceptive method use in Australia. J Biosoc Sci 2010; 42(1):43-58.

4. Steel A, Frawley J, Dobson A, Jackson C, Lucke J, Tooth L, Brown W, Byle J, Mishra G. Women's Health in NSWa life-course approach in evidence check rapid review. Ultimo: Sax Institute; 2013.

5. Fetterolf J, Sanchez D. The Cost and Benefits of Perceived Sexual agency for men and Women. Archives of sexual Behavior 2015; 44(4):961-970.

6. Figueiredo L, Silva R, Silva I, Souza K, Silva F. Percepção de mulheres casadas sobre o risco de infecção pelo hiv e o comportamento preventivo. Revista Enfermagem UERJ 2014; 21(2):2-18

7. Carlsson-Lalloo E, Rusner M, Mellgren A, Berg M. Sexuality and Reproduction in HIV Positive Women. A Meta Synthesis. Aids patient care STDS 2016; 30(2):5669.

8. Carvalhaes FF, Teixeira-Filho FS. Histórias de vida de mulheres HIV+ativistas: mudanças e permanências. Estudos Feministas 2012; 20(2):377-398

9. Boileau C, Clark S, Bignami-Van Assche S, Poulin M, Reniers G, Watkins SC, Kohler HP, Heymann SJ. Sexual and marital trajectories and HIV infection among ever-married women in rural Malawi. Sex Transm Infect 2009; 85(Supl. I):i27-i33.

10. Darak S, Mills M, Kulkarni V, Kulkarni S, Hutter I, Janssen F. Trajectories of Childbearing among HIV Infected Indian Women: A Sequence Analysis Approach. PLoS ONE 2015; 10(4):e0124537.

11. Santos NJS, Buchalla CM, Ventura EF, Bugamelli L, Paiva V. Mulheres HIV Positivas, Reprodução e Sexualidade. Rev Saude Publica 2002; 36(4):12-23.

12. Pilecco FB, Teixeira LB, Vigo Á, Knauth DR. Post-diagnosis abortion in women living with HIV/Aids in the south of Brazil. Cien Saude Colet 2015; 20(5):15211530 .

13. Pilecco FB, Teixeira LB, Vigo Á, Dewey M, Knauth DR. Lifetime Induced Abortion: A Comparison between Women Living and Not Living with HIV. Plos One 2014; 9:e95570.

14. Villela WV, Barbosa RM, Portella AP, Oliveira LA. Motivos e circunstâncias para o aborto induzido entre mulheres vivendo com HIV no Brasil. Cien Saude Colet 2012; 17(7):1709-1719.

15. Monteiro S, Villela WV, Soares PS, Pinho A, Fraga L. Protective" silence surrounding AIDS: Reasons and implications of non-disclosure among pregnant women living with HIV in Rio de Janeiro (Brazil). Global Public Health 2016; no prelo.

16. Barbosa RM, Pinho A, Santos NS, Villela WV. Exploring the relationship between induced abortion and HIV infection in Brazil. Reproductive Health Matters 2012; 20(Supl. 39):80-89.
17. Brasil. Ministério da Saúde (MS). Boletim epidemiológico Aids e DST. Brasília: MS; 2015.

18. Santos NJ, Barbosa RM, Pinho A, Villela WV, Aidar T, Filipe E. Contextos de vulnerabilidade para o HIV entre mulheres brasileiras. Cad Saude Publica 2009; 25(Supl. 2):321-333.

19. Mazaderani F, Paparini S. The stories we tell: Qualitative research interviews, talking technologies and the 'normalisation' of life with HIV. Soc Sci Med 2015 131:66-73.

20. Greco DB. Thirty years of confronting the Aids epidemic in Brazil, 1985-2015. Cien Saude Colet 2016 21(5):1553-1564.

21. Shisana O, Zungu N, Evans M, Risher K, Rehle T, Celentano D. The case for expanding the definition of 'key populations' to include high-risk groups in the general population to improve targeted HIV prevention efforts. S Afr Med J 2015; 105(8):664-669.

22. Villela WV, Barbosa RM. Prevenção da transmissão heterossexual do HIV entre mulheres: é possível pensar estratégias sem considerar suas demandas reprodutivas? Revista Brasileira de Epidemiologia 2015; 18(Supl. 1):131-142.

23. Rocha S, Vieira A, Lyra J. Silenciosa conveniência: mulheres e Aids. Revista Brasileira de Ciência Política 2013 11:119-141.

24. Villela WV, Monteiro SS. Gênero, estigma e saúde: reflexões a partir da prostituição, do aborto e do HIV/ aids entre mulheres. Epidemiologia e Serviços de Saúde 2015; 24(3):531-540.

25. Costa TL, Oliveira DC, Formozo GA. Qualidade de vida e AIDS sob a ótica de pessoas vivendo com o agravo: contribuição preliminar da abordagem estrutural das representações sociais. Cad Saude Publica 2015; 31(2):365-376

26. Valle CG. Biosocial Activism Identities and citizenship: Making up "people living with HIV and Aids in Brazil. Vibrant 2015; 2(2):28-70.

27. Shefer TA. Resisting the binarism of victim and agent Critical reflections on 20 years of scholarship on young women and heterosexual practices in South African contexts Global Public Health 2016; 11(1-2):211-223.

28. Granjeiro A, Castanheira ER, Nemes MIB. A re-emergência da epidemia de Aids no Brasil :desafios e perspectivas para o seu enfrentamento Interface: Comunicação, Saúde e Educação. 2015; 19(52):5-6

29. Brasil. Ministério da Saúde (MS). Dados Epidemiológicos HIV/AIDS. Brasília: MS; 2015.

Artigo apresentado em 26/05/2016

Aprovado em 22/07/2016

Versão final apresentada em 24/07/2016 